\title{
A century of parasitology: 1914-2014
}

John Janovy, Jr

School of Biological Sciences, University of Nebraska-Lincoln, U.S.A.
The hundred years between 28 June 1914, when the assassination of Austrian Archduke Franz Ferdinand precipitated World War I, and 27 July 2014, closing day of the American Society of Parasitologists' 89th annual meeting, represent one of the most stressful, complex, yet in some ways wondrous, periods of human history. Samantha Power (2002) called this time the "Age of Genocide;" Albert Einstein's equations completely re-structured our image of the universe; nuclear weapons entered our political negotiations; and, molecular biologists obliterated some of our most cherished views of nature. A decade after the Wright brothers' first sustained flight in a heavier-than-air craft, in December 1903, military airplanes took to the skies over Europe; today, some authors claim that airports are our current versions of the thirteenth-century cathedrals (Binney, 1999). Robert Goddard began his experiments with solid-fueled rockets in 1915 (Lehman, 1963); by 2014, intercontinental ballistic missiles were hiding in silos scattered across the Great Plains of North America, an International Space Station circled Earth, and the first Apollo moon landing was a mostly forgotten historical event. Even as we spent the past century obliterating much of Earth's terrestrial biological diversity by clearing tropical forests, satellite telescopes were discovering exo-planets at an increasing rate. In 1914, a successful scientist like H. B. Ward, founder of the American Society of Parasitologists as well as driving force behind a new scientific journal, The Journal of Parasitology, could buy a new Royal Model 10 typewriter; a century later we stop teaching cursive to elementary school students largely because kids are communicating via QWERTY keyboards (designed in 1873) on hand-helds with temperature-sensitive screens. Senior citizens today can recite, largely from personal experience, the origin and impact of what we now call the "Information Age."

The new century in which we live should be an interesting one too, with projected climate change potentially wreaking havoc on coastal ecosystems and human populations expected to (phrased euphemistically) "level off." Some things have not changed very much, however; parasitic organisms still infect not only humans and our domestic animals, but also, to our knowledge, virtually every eukaryotic species on planet Earth. Despite Ronald Ross' (1902) claim, in his Nobel Prize acceptance speech-“It is my privilege in this lecture to describe particularly the steps by which this great problem has at length received its full solution" - malaria remains one of humanity's most persistent scourges. Schistosomiasis, filariasis, and geohelminth infections still cause untold misery, along with their protistan counterparts such as leishmaniasis and amebiasis, especially in the tropics. But these infectious diseases also have inspired generations of parasitologists to apply their time, talents, and intellectual resources to find cures, or develop control methods, and thus provide relief from the economic and social burdens caused by parasitic organisms (Kuris, 2012; Loker, 2013).

In their quests to develop treatment and control technologies, parasitologists have indeed produced some major successes over the past century, but in the process they also have made conceptual contributions that

A Century of Parasitology: Discoveries, ideas and lessons learned by scientists who published in The Journal of Parasitology, 1914-2014, First Edition. Edited by John Janovy, Jr and Gerald W. Esch.

() 2016 John Wiley \& Sons, Ltd. Published 2016 by John Wiley \& Sons, Ltd. 
might arguably be described as "metaparasitology" — an intellectual realm that includes the "rules" for pursuing the discipline. Although it may not always have been their intent, parasitologists have done research that in turn shapes our ideas about interactions between hosts and parasites. Excellent examples, among many, of concepts published very early if not originally in The Journal of Parasitology, include molecular mimicry in schistosomes (Damian, 1962, 1964, 1987), the relative immortality of cestodes (Read, 1967), and amphiparatenesis in Alaria marcianae as demonstrated by Shoop and Corkum (1987), who then extended the concept to those nematode species known to exhibit developmental arrest and transplacental transmission. With time, sometimes a surprisingly short time in historical terms, these kinds of contributions become principles of parasitism - the most common way of life among animals and animal-like eukaryotes.

Our goal in assembling this volume of contributed chapters is to bring the phenomenon of concept-driven research to the forefront, especially in the minds of younger readers. We also hope to provide historical perspective in the form of lessons learned from both successful and unsuccessful research endeavors. Thus, our contributing authors have been asked to step outside their immediate comfort zones, those places so often constructed and constrained by legitimate demands of proper methodology, statistical analysis, correct identification, and anonymous reviewers, and instead reflect on the historical development of their subjects. To quote from an early memo to our authors:

In most of the correspondence and discussion so far, we've mentioned the hope that these chapters would be heavy on ideas, and that authors would show us how research has inspired further work, how concepts demonstrated by particular papers have served a heuristic role in parasitology, and how historical precedents have been established. Our hope is that this volume will be unique in its role as a demonstration of how parasitologists think about their discipline and sub-disciplines, and how our material provides so many research opportunities yet can be quite uncooperative in sometimes unexpected ways. In the best of all worlds, students read this book, and come away with new ideas about their current research, an expanded view of how parasitologists pursue their careers, and a feeling that their own work, sometimes with obscure organisms that have little economic importance, has the potential to open up new areas of investigation. In other words, we understand that the subject is science, but we encourage all of you to think in terms of the history of science and what we have learned about how to do our science from having done it for years, if not decades.
Nobody needs reminded that mid-career scientists are fully occupied, and that statement certainly applies to the authors who have contributed to this volume. It is true, as Asa Chandler noted in his Presidential address during the 1945 American Society of Parasitologists meeting (Chandler, 1946), that parasitologists are "slow in going to seed," so even our retired colleagues are busy with projects that consume their time and energies. Therefore, as must be the case for all such ambitious endeavors, this particular volume is not as inclusive as it might have been. But in our defense, after reading the initial chapter drafts, we editors came to the conclusion that it would require a whole shelf of such books to truly do the subject justice. We expect that some of you will take on this future task!

We also hope that this book sells enough copies to generate some net income. By written agreement between the editors and publisher, such "profits" have been assigned to the American Society of Parasitologists for support of The Journal of Parasitology, and especially to defray page charges for authors who have accepted papers, but are not in a position to pay costs for longer articles or essential color figures. The Journal of Parasitology is indeed an amazing publication with very long shelf life, rather like some of the authors who have published in it. If a student is able to read through a single issue, for example, and both understand and appreciate most of the work reported, that student will be broadly educated in a decidedly empowering manner. So our real dream, beyond some welcome support for authors who publish in the Journal, is that these chapters, which are mostly senior scientists' reflections on how our research has been shaped by ideas, will serve as conversation starters for younger scientists.

\section{Literature cited}

Binney, M. 1999. Airport builders. Academy Editions, Chichester, U.K., 223 p.

Chandler, A. C. 1946. The making of a parasitologist. Journal of Parasitology 32: 213-221.

Damian, R. T. 1962. A theory of immunoselection for eclipsed antigens of parasites and its implications for the problem of antigenic polymorphism in man. Journal of Parasitology 48: 16.

1964. Mimicry: Antigen sharing by parasite and host and its consequences. American Naturalist 98: 129-149. 1987. The exploitation of host immune response by parasites. Journal of Parasitology 73: 1-13. 
Kuris, A. M. 2012. The global burden of human parasites: Who and where are they? How are they transmitted? Journal of Parasitology 98: 1056-1064.

Lehman, M. 1963. This high man; The life of Robert H. Goddard. Farrar, Straus, New York, NY, 430 p.

Loker, E. S. 2013. This de-wormed world? Journal of Parasitology 99: 933-942.

Power, S. 2002. "A problem from hell": America and the age of genocide. Basic Books, New York, NY, 610 p
Read, C. P. 1967. Longevity of the tapeworm, Hymenolepis diminuta. Journal of Parasitology 53: 1055-1056.

Ross, R. 1902. Researches on malaria. In Nobel lectures, physiology or medicine, Nobel Foundation. Elsevier, Amsterdam, The Netherlands, p. 26-116.

Shoop, W. L., and K. C. Corkum. 1987. Maternal transmission by Alaria marcianae and the concept of amphiparatenesis. Journal of Parasitology 73: 110-115. 
